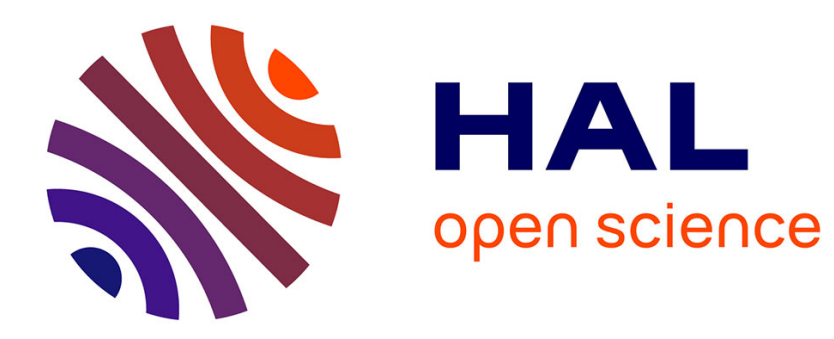

\title{
New potentials for the laser crystals with second and third optical nonlinearities
}

\author{
A. Kaminskii
}

\section{To cite this version:}

A. Kaminskii. New potentials for the laser crystals with second and third optical nonlinearities. Journal de Physique IV Proceedings, 1994, 04 (C4), pp.C4-297-C4-300. 10.1051/jp4:1994473 . jpa00252736

\section{HAL Id: jpa-00252736 https://hal.science/jpa-00252736}

Submitted on 1 Jan 1994

HAL is a multi-disciplinary open access archive for the deposit and dissemination of scientific research documents, whether they are published or not. The documents may come from teaching and research institutions in France or abroad, or from public or private research centers.
L'archive ouverte pluridisciplinaire HAL, est destinée au dépôt et à la diffusion de documents scientifiques de niveau recherche, publiés ou non, émanant des établissements d'enseignement et de recherche français ou étrangers, des laboratoires publics ou privés. 


\title{
New potentials for the laser crystals with second and third optical nonlinearities
}

\author{
A.A. KAMINSKII \\ A.V. Shubnikov Institute of Crystallography, Russian Academy of Sciences, 117333 Moscow, Russia
}

Some new ideas for achieving stimulated-emission generation in laser crystais doped with $\mathrm{Ln}^{3+}$ ions are proposed. They are based on a pumping involving second garmonic generation and stimulated-Raman scattering phenomena. These ideas have benn implemented experimenta11y.

The structural diversity of activated insulating crystals, their wide range of physical properties, and their essentially inexhaustible spectroscopic potential constitute a gold mine of opportunities for developing new operating laser schemes and principles for achieving stimulated emission (SE) in these crystals. Among the many known laser compounds /1/, nonlineat (acentric) crystals axe distinguished by a unique set of properties. In particular, they have already provided one of the most elegant advances in experimental physics and quantum electronics: crystalline lasers in which self-doubling of lasing frequency occurs (see, for example /2-5/). A distinctive features of these lasers is that the SE is excited and its frequency is converted into the second harmonic in the same nonlinear laser element.

No less interesting is the "self-stimulated Raman scattering" which was recen ly observed: a frequency conversion of $\mathrm{SE}$ of the potassium-rare-earth tungstenates doped with $\mathrm{Nd}^{3+}$ ions /6,7/. Again, the effect occurs in a single laser crystal. In addition to the fundamental SE, it is accompanied by the generation of components at Stokes and anti-Stokes Raman-scattering frequencies.

These nonlinear-optics effects also underlie the new principles for achieving SE in activated crystals which we discuss below. Here, however, these effects are utilized in a completely different way. In the experiments which we just mentioned, the self-doubling (second harmonic generation) and stimulated-Raman conver- 
sion resulted from intrinsic $\mathrm{SE}$ of laser crystals, and they led to an enrichment of the output spectra of these crystals /8/. In the operating schemes proposed belo' in contrast, these effects are called on to play a different role: to convert the emission frequency of external pump lasers in order to match the active absorption bands of the lasing ions, i.e., to create the conditions requered for achieving $\mathrm{SE}$ of these activator ions.

Our generation experiments in these new laser schemes used acentric LaBGeO 5 (space group $\mathrm{C}_{3}^{2}$ ) and $\mathrm{LiNbO}_{3}$ :MgO $\left(\mathrm{C}_{3 \mathrm{v}}^{6}\right)$ siningle crystals doped with $\mathrm{Nd}^{3+}$ ions and stimulated-Raman-active crystals of the $\mathrm{KY}\left(\mathrm{WO}_{4}\right)_{2}$ type $\left(\mathrm{C}_{2 \mathrm{~h}}^{6}\right)$ doped with $\mathrm{Er}^{3+}$ ions, which are single-centered crystals with ordered structure. Fig. 1 explains the expe rimental conditions and the nonlinear-conversion processes involving absorption of external laser light in the matrix crystals and the laser channels for the excitation and generation of $\mathrm{SE}$.

Let us look at some properties of these crystals. The $\mathrm{LaBGeO}_{5}: \mathrm{Nd}^{3+}$ crystal has an atomic neodymium concentration $\mathrm{C}_{\mathrm{Nd}}=1.4 \%$. The angle between the geometric axis (F) and the crystallographyc axis (c) is equal to the phase-matching angle, Fc= $=\theta_{\mathrm{m}} \simeq 54^{\circ}$. The length is $1=12 \mathrm{~mm}$, and the diameter $4 \mathrm{~m}$. In the LiNbo $3: \mathrm{MgO}_{\mathrm{Nd}}{ }^{3+} \mathrm{crys}^{-}$ tal, the neodymium concentration is $C_{N d} \approx 0.2 \%$. In this case we have $\theta_{m} \approx 70^{\circ}, 1=10$ $\mathrm{mm}$, and a diameter of $5 \mathrm{~mm}$. The $\mathrm{KY}\left(\mathrm{WO}_{4}\right)_{2}: \mathrm{Er}^{3+}$ crystal has $\mathrm{C}_{\mathrm{Er}} \approx 30 \%, F|| b, 1=40 \mathrm{~mm}$, and a diameter of $6 \mathrm{~mm}$. The $\mathrm{KGd}\left(\mathrm{WO}_{4}\right)_{2}: \mathrm{Ex}^{3+}$ crystal has the same properties. The $\mathrm{KEr}\left(\mathrm{WO}_{4}\right)_{2}: \mathrm{Er}^{3+}$ crystal has $\mathrm{C}_{\mathrm{Er}}=100 \%, \mathrm{~F} \mid \mathrm{fb}, 1=25 \mathrm{~mm}$, and a diameter of $6 \mathrm{~mm}$. The $\mathrm{KLu}\left(\mathrm{WO}_{4}\right)_{2}: \mathrm{Er}^{3+}$ crystal has $\mathrm{C}_{\mathrm{Er}}=25 \%, \mathrm{~F}|| \mathrm{b}, 1=30 \mathrm{~mm}$, and a diameter $6 \mathrm{~mm}$. No anti-ref lection coatings were applied to the plane-parallei ends of the laser elements in this stage of the research.

We have a few words 'regarding the "external" pump Q-switched lasers and hemispherical optical resonators used for the excitation of SE in our crystals containing $\mathrm{Nd}^{3+}\left({ }^{4} \mathrm{~F}_{3 / 2} \rightarrow{ }^{4} \mathrm{I}_{13 / 2}\right.$ lasing channel) and $\mathrm{Er}^{3+}\left({ }^{4} \mathrm{I}_{11 / 2} \rightarrow{ }^{4} \mathrm{I}_{13 / 2}\right)$ in these new operating schemes. Two types of pulse pump lasers were used $\left(\tau_{p}=10-15 \mathrm{~ns}, \mathrm{E}_{\mathrm{p}}=10-15\right.$ $\mathrm{mJ}):$ based on $\mathrm{LaF}_{3}: \mathrm{Nd}^{3+} / \lambda=1.0406 /$ um $\left(9609 \mathrm{~cm}^{-1}\right) /$ and $\mathrm{Al}_{2} \mathrm{O}_{3}: \mathrm{Ti}^{3+} / \lambda=0.752$, um 
(13300 $\left.\mathrm{cm}^{-1}\right)$ crystals. The polarized laser emission from these crystals was focuced by a lens $(f=20 \mathrm{~cm})$ into the active elements through a plane mirror of the resonator (whose transmission at pumping wavelengths was about $80 \%$ ). This mirror was pressed tightly against the active element. The spherical mirror differed in curvature. The radius of curvature was $r=5 \mathrm{~cm}$ for the experiments with the crystals containing Nd ions, while it was $r=25 \mathrm{~mm}$ for the crystals with $E r^{3+}$ activators. These mirrors had a high reflection coefficient (no less than 99\%) both that the frequencies of the SE of the our activator ions and at the fequencies of the pump emission converted by the crystal-hosts. The spectra of the SE from these crystals was studied with the help of high-resolution grating monochromators and a GA-lM avalanche Ge-photodiede.

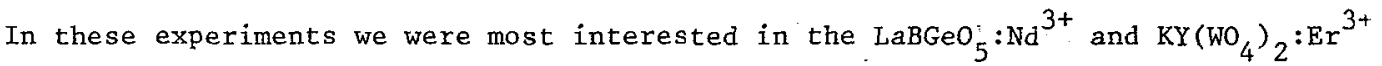
crystals. When the pump-power density exceeded a level of about $0.1 \mathrm{GW} / \mathrm{cm}^{2}$ in the $\mathrm{first}$ of these crystals, the second harmonic $\left(v \simeq 19220 \mathrm{~cm}^{-1}\right)$ excited $\mathrm{SE}$ of $\mathrm{Nd}$ ions (by the absorption channels ${ }^{4} \mathrm{I}_{9 / 2} \rightarrow{ }^{4} \mathrm{G}_{7 / 2,9 / 2},{ }^{2} \mathrm{~K}_{13 / 2}$; followed by a nonradiative relaxation of the excitation to levels of metastable ${ }^{4} \mathrm{~F}_{3 / 2}$ state, Fig. 1a). This crystal emitted $\pi$-polarized $\mathrm{SE}$ at the 1.3141 , um wavelength. The coefficient of the conversion of pump emission by the $\mathrm{LaBGeO}_{5}$ crystal into second harmonic was about $5 \%$. Despite the large quadratic nonlinear susceptibility $x^{(2)}$ of our second nonlinear crystal $\mathrm{LiNbO}_{3}: \mathrm{MgO}^{2}$ much higher pupm densities were required to achieve SE of $\mathrm{Nd}^{3+}$ in that case.

In the monoclinic $\mathrm{KY}\left(\mathrm{WO}_{4}\right)_{2}: \mathrm{Er}^{3+}$ crystal, SE was achived on inter-Stark transitions $\left(\lambda_{\mathrm{SE}}=2.6887\right.$ and 2.8070 , um $)$ of the $3-$ um self-saturating ${ }^{4} \mathrm{I}_{11 / 2}{ }^{-{ }^{4}} \mathrm{I}_{13 / 2}$ channe 1 : of $\mathrm{Er}^{3+}$ ions at a pump-power density of about $0.3 \mathrm{GW} / \mathrm{cm}^{2}$. As can be seen from Fig. $1 \mathrm{~b}$, $\mathrm{Er}^{3+}$ activators are excited in this case by emission at the first Stokes components, $\omega_{S}=\omega^{-\omega_{R S}}$, of the pump emission at $\omega\left(\omega_{\mathrm{RS}} \approx 900 \mathrm{~cm}^{-1}\right.$ is the frequency of the stimulated-Raman-active optical vibrational mode of the tetrahedral $\mathrm{wo}_{4}^{2-}$ complex of the crystal-host). In view of the high efficiency of stimulated-Raman conversion in crystals 0 this type, which ranges up to $60 \% / 9 /$, it can be assumed that their cubic nonlinear susceptibility $x^{(3)}$ is fairly high. Unfortunately, the efficiency of stimulated-Raman conversion in our experiments did not exceed 7-9\%. The 3-, um SE of Er ${ }^{3+}$ ions in the three other monoclinic tungstenates was excited at approximately the same pump-power densities. 
1. A.A.Kaminskii, Ann.Phys. (Paris) 16, 639 (1991).

2. L:F.Johnson, A.A.Ballman, J. Appl. Phys., 40, 297 (1969).

3. V.G.Dmitriev, E.V.Raevskii, N.M.Rubina et al;, Pisma Zh.Tekh.Fiz., 5, 1400 (1979)

4. L.M.Dorozhkin, I.I.Kuratev, N.I.Leonyuk et al,, Pisma Zh.Tekh.Fiz.,7, 1297 (1981)

5. A.A.Kaminskii, A.V.Butashin, I.A.Maslyanizin et al, Phys.Status Solidi (a), 125,671 (1991).

6. A.M.Ivanyuk, M.A.Ter-Pogosyan,'P.A.Shakhverdov et.al., Opt.Spektrosk., 59, 950 (2985).

7. K.Andryunas, Yu.Vishchakas, V.Kabelka et.al., Pisma Eksp.Teor.Fiz?, 42, 333 (1985

8. A.A.Kaminskii, Quantum Electronics 23, 457 (1993).

9. V.A.Berenberg, S.N.Karpukhin; I.V.Mochalov; Kvant;Elektron., 14, 1849 (1987).

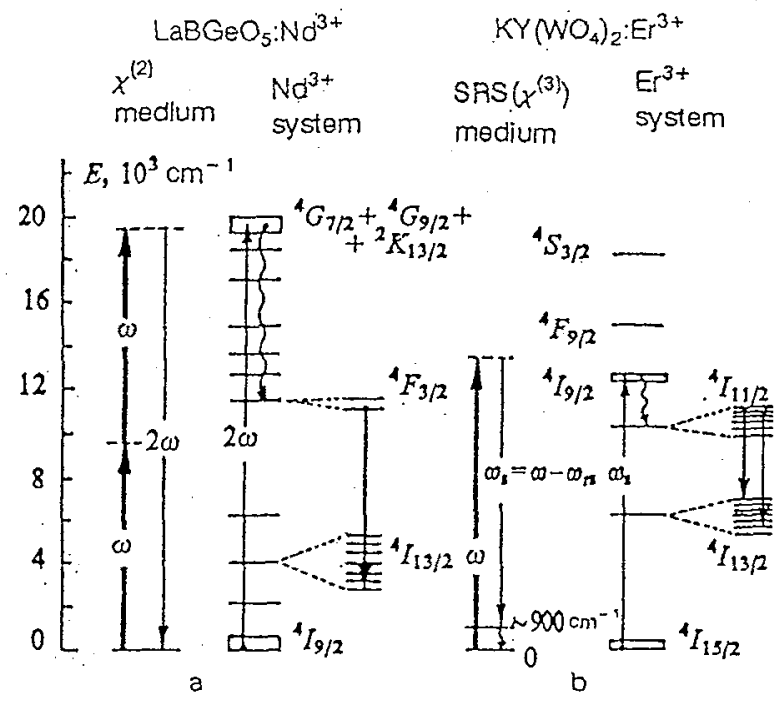

FIG. 1. Simplifed diagrams of the excitation of stimulated emission in spectrum-converting pumping processes in (a) nonlinear and.(b) stimulated-Raman-active . laser crystals doped with $\mathrm{Ln}^{3+}$ activator ions. The unconverted pump is represented by double arrows, and the converted pump by ordinary arrows. The heavy arrow's show channels for stimulated emission of the $\mathrm{Ln}^{3+}$ jons, while the wavy arrows show radiationless processes. 